\title{
Primary Neuroendocrine Carcinoma of the Breast: A Case Report and Review of the Literature
}

\author{
H. Bhiri' ${ }^{1}$, S. Zaied ${ }^{1}$, H. Mhabrech ${ }^{2}$, I. Abbes ${ }^{1}$, O. Zoukar ${ }^{3}$, H. Bargaoui ${ }^{3}$, A. Korbi ${ }^{3}$, R. Falah ${ }^{3}$, \\ A. Ben Salem², M. Njima4, H. Laajili ${ }^{3}$, A. Daldoul ${ }^{*}$ \\ ${ }^{1}$ Medical Oncology Department, Fattouma Bourguiba Hospital, University of Monastir, Monastir, Tunisia \\ ${ }^{2}$ Radiology Department, Omran Hospital, University of Monastir, Monastir, Tunisia \\ ${ }^{3}$ Gynecology Department, Omran Hospital, University of Monastir, Monastir, Tunisia \\ ${ }^{4}$ Pathology Department, Fattouma Bourguiba Hospital, University of Monastir, Monastir, Tunisia \\ Email: *amira.krir@outlook.com
}

How to cite this paper: Bhiri, H., Zaied, S., Mhabrech, H., Abbes, I., Zoukar, O., Bargaoui, H., Korbi, A., Falah, R., Ben Salem, A., Njima, M., Laajili, H. and Daldoul, A. (2017) Primary Neuroendocrine Carcinoma of the Breast: A Case Report and Review of the Literature. Open Access Library Journal, 4: e3892.

https://doi.org/10.4236/oalib.1103892

Received: August 17, 2017

Accepted: November 28, 2017

Published: December 1, 2017

Copyright $\odot 2017$ by authors and Open Access Library Inc.

This work is licensed under the Creative Commons Attribution International License (CC BY 4.0).

http://creativecommons.org/licenses/by/4.0/

\begin{abstract}
Primary neuroendocrine carcinoma of the breast is a rare tumor that has been considered special features within conventional breast carcinomas until recently. In this article, we present a case report of a 77-year-old woman with a metastatic grade I primary neuroendocrine carcinoma of the breast that has been growing for seven years. The patient was treated with hormone therapy with good outcome.
\end{abstract}

\section{Subject Areas}

Oncology

\section{Keywords}

Primary, Carcinoma, Neuroendocrine, Breast, Chemotherapy

\section{Introduction}

Neuroendocrine tumors essentially originate in the broncho-pulmonary system and gastro-intestinal tract [1]. These tumors are rare. They account for less than $0,1 \%$ of all breast cancers, and less than $1 \%$ of neuro-endocrine tumors [2] [3] [4]. Primary neuroendocrine breast carcinomas (NEBC) have been considered special features within conventional breast carcinomas until recently [5]. These tumors mostly affect elderly patients [4], and their prognosis is relatively more favorable than the majority of breast cancers [6]. 
In this article, we present a case report of a primary NEBC, and a review of the literature related to this histological type. Furthermore, we discuss epidemiological and morphological features and the immunohistochemical profile of these rare tumors.

\section{Case Report}

A 77 year old woman with a medical history of hypertension and diabetes presented to the emergency department for dyspnea. Imaging examinations showed a pleural effusion and the closed pleural biopsy revealed the presence of carcinomatous cells.

The patient declared the presence of a mass in the right breast that has been growing for seven years, and clinical examination identified a carcinomatous mastitis (Figure 1).

Mammography and ultrasound showed tow voluminous masses, almost occupying the totality of right breast, with speculated margins and satellite lymphadenopathies.

Core biopsy was performed and an atomopathological analysis was in favor of a grade I primary neuroendocrine carcinoma of the breast (Figure 2 and Figure 3). At the immunohistochemical staining, the tumor cells were positive for synaptophys in and CK7 markers, and negative for chromogranin and CK20. Moreover, estrogen and progesterone receptors were positive in $100 \%$ of the tumor cells (Figure 4).

The work-up for extension detected pulmonary and pleural metastatsis. The tumor was classified as T4d N1 M1. The patient received hormonal therapy with tamoxifen. After 10 months of treatment, primary tumor and distant metastasis

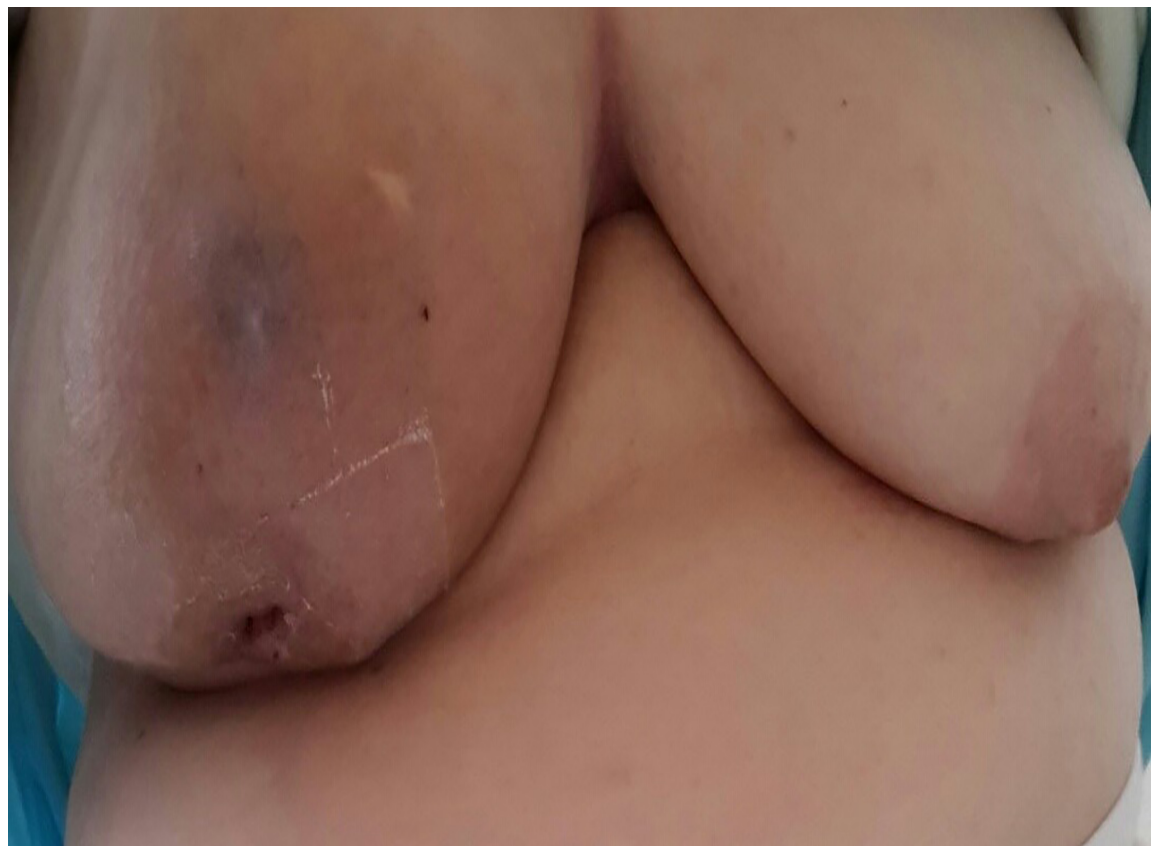

Figure 1. Carcinomatous mastitis. 


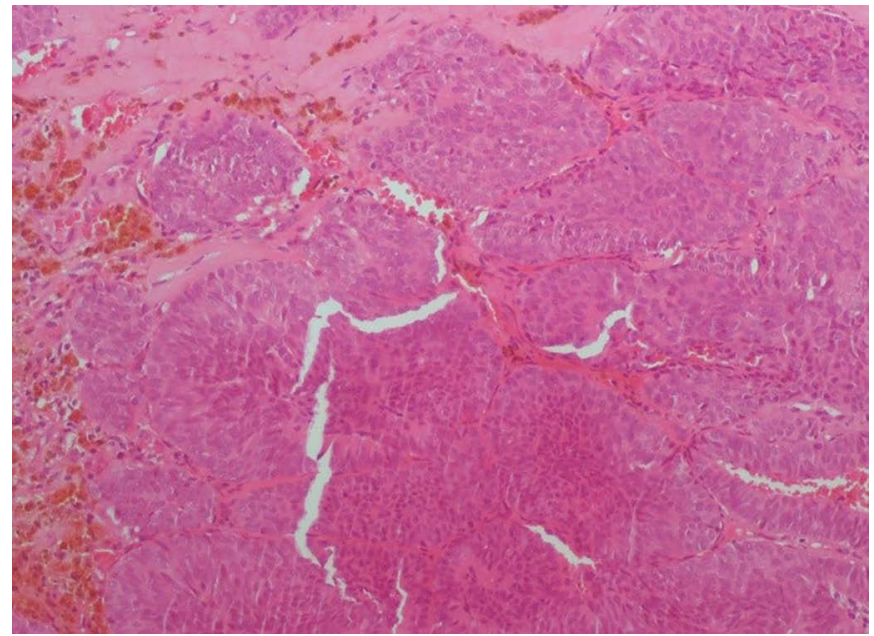

Figure 2. Tumor cell population separated by a more or less abundant connective tissue with significant deposition of hemosiderin (H \& E 100×).

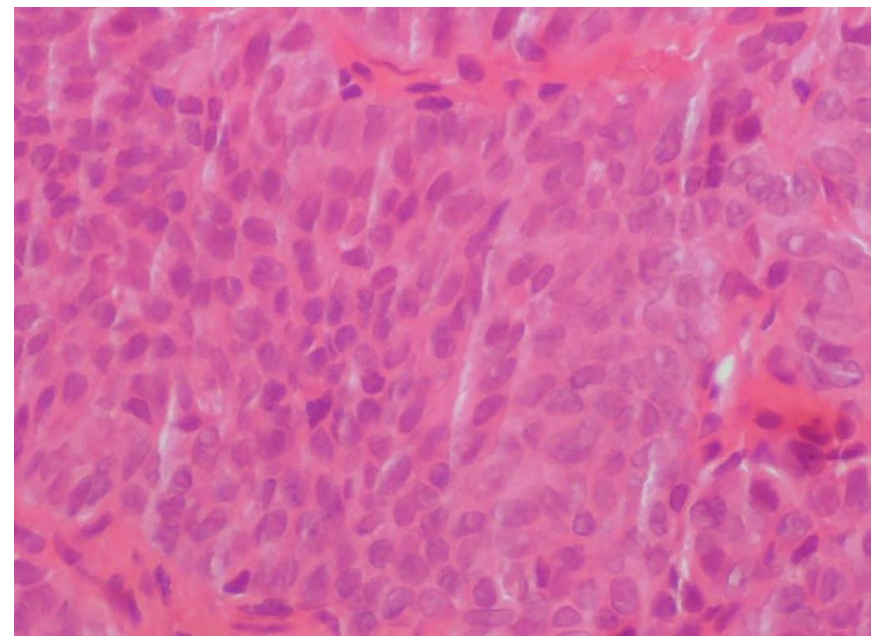

Figure 3. Monomorphic tumor cells with abundant eosinophilic cytoplasm, and a low mitotic activity (H \& E 400×).

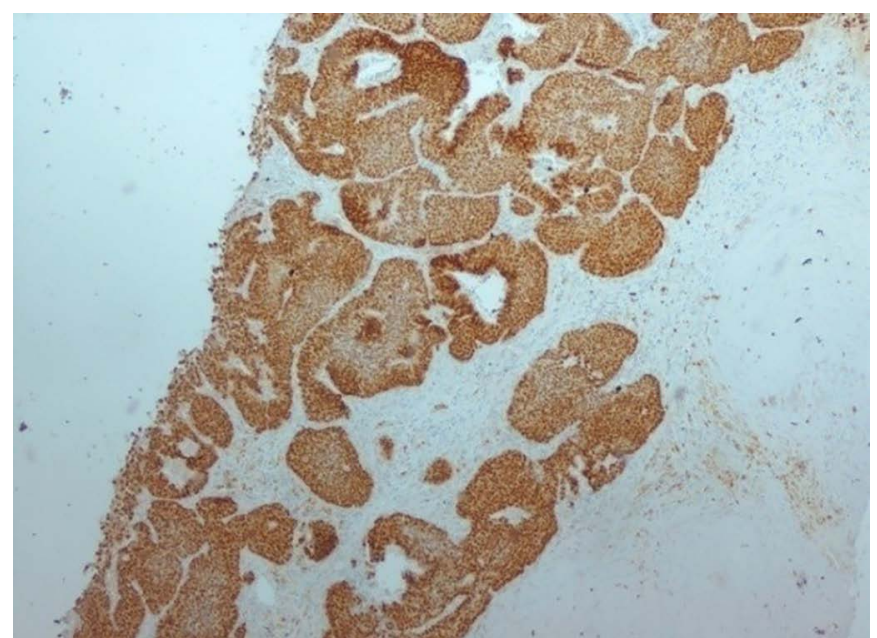

Figure 4. Strong and diffuse positivity for estrogen receptors (100x). 
have regressed completely. Since October 2016 she received hormonal treatment with letrozole for bone metastasis progression.

\section{Discussion}

NEBC are a rare entity of breast cancer [2] [3] [4]. In 1947, germanpathologisVolger [7] was the first to describe the existence of neuroendocrine cells in breast tissue and it was not until 1977, when Cubilla and Woodruff [8] reported the first eight cases of primary NEBC.

Since then, this entity is mostly described in the form of small series [5] [6] [9] or as individual case reports [10] [11]. Günhan-Bilgen et al. [9] and Lopez-Bonet et al. [5] found that these tumors represent $0.27 \%$ and $0.51 \%$ of breast cancer cases respectively. More recently, in Rovera et al.'s report [6], among 2829 patients who underwent surgery for breast cancer, there were 61 patients with NEBC. According to the WHO, the incidence of NEBC is less than 1\% [4].

These tumors mostly affect elderly patients [4]. In Bonet's report [5], the median age was 63 years. Only one patient was 35 years old, the rest of the patients were above 50 years old. Rovera [6] reports a mean age at diagnosis of 70 years, and $90.5 \%$ of the patients were in menopause. In agreement with previous reports, our patient had 77 years old.

Clinical presentation of NEBC is similar to other breast cancers with no specific sign in their favor. They usually present as a palpable mass in the breast [12] [13]. There has been only one report to date of a primary neuroendocrine carcinoma of the breast with clinical features of inflammatory breast carcinoma [14], such with our patient.

Reports on NEBC imaging are limited. NEBC appears hypodense on mammography, as round or irregularly shaped masses with variable margins either speculated, indistinct, circumscribed, or obscured [14]. On ultrasonography, such tumors may present as either morphologically irregular solid lesions or lesions with a cystic component, with ill defined margins and increased vascularization [11]. In the present report, the tumor had speculated margins.

These tumors do not have any distinctive characteristics on radiological examination[15]. However, unlike common breast carcinomas, NEBC may appear as sharply circumscribed masses with no associated microcalcifications on mammography mimicking a benign tumor [2]. On MRI, they appear as irregular masses with rim enhancement and malignant kinetic characteristics, and early rapid and delayed washout enhancement [14].

Because of the lack of specific clinical or radiological features, the diagnosis of NEBC is based on their histological growth pattern and immunohistochemical staining for neuroendocrine markers [16]. NEBC have recently been recognized as a separate diagnostic entity by the WHO. The diagnosis is based on presence of morphologic neuroendocrine features, such as in gastro-intestinal tract, pancreatic or pulmonary neuroendocrine tumors, and neuroendocrine markers should be expressed in more than $50 \%$ of tumor cells [4]. In fact, a focal neu- 
roendocrine component can be detected in a large number of breast cancers [6].

Chromagranine and synaptophysine seem to be the most sensitive and specific markers and they strongly support the diagnosis of NEBC [17]. CD-56 has also been demonstrated to be of value, although it is less specific [18]. In fact, all the NEBC cases in Bonet's report [5] were negative for CD56. The authors suggested that this fact likely relates to the tendency of theanti-CD56 monoclonal antibody to preferentially immunoreact against undifferentiated small cell carcinomas but not against more differentiated neuroendocrine carcinomas.

Other neuroendocrine markers including neuron-specific enolase (NSE) and Leu 7 (CD-57) are also commonly used to evaluate neuroendocrine differentiation in breast carcinomas [18]. In the present report, immunohistochemical staining was positive for synaptophysin and CK7markers, and negative for chromogranin and CK20.

While positivity of hormonal receptors is almost constant, ranging from 90 to $100 \%$ of NEBC, the expression of HER-2 is less frequent in breast carcinomas with neuroendocrine features [5] [6]. In agreement with other reports, estrogen and progesterone receptors were positive in $100 \%$ of the tumor cells of our patient.

Such as with other histological breast cancer types, surgical resection is the main treatment for NEBC. However, there is no standard treatment protocol for these carcinomas concerning system icendocrine and immunotherapy given the rare incidence of this entity. Several chemotherapy regimens have been reported, including include FAC (fluorouracil, doxorubicin, cyclophosphamide), CMF (cyclophosphamide, methotrexate, fluorouracil), CAE (cyclophosphamide, doxorubicin, etoposide), and CP (cisplatin, etoposide) as single agents or in combination [18]. In Lee's report [14], various regimens (six cycles of cicplatin and etoposide, six cycles of docetaxel and three cycles of eribulin) were attempted for advanced stage inflammatory NEBC, however the tumor showed poor response and the patient developed metastatic lesions. Other case reports showed effectiveness of platinum based chemotherapy and endocrine therapy [19] [20]. In agreement with these reports, our patient showed good response to endocrine therapy. However, the optimal treatment strategy remains unclear.

Breast cancer with endocrine component has also been controversial in terms of his clinical outcome. In Rovera's report [6], 96 patients with NEBC were divided into two groups; the first group was composed of 61 patients with expression of a neuroendocrine marker in more than $50 \%$ of neoplastic cells, and the second was composed of 35 patients with expression of neuroendocrine markers in less than $50 \%$ of the tumor cells. This study showed a better prognosis in patients with NEBC compared to breast carcinomas with a minor neuroendocrine component and to conventional invasive ductual or lobular cancers.

However, in another study of 74 cases of invasive NEBC of the breast, these cancers were found to have worse clinical outcome compared with age- and stage-matched controls of invasive ductual carcinoma [21]. 
The 10-year survival of patients with NEBC component is reported to be $87 \%$ [6]. Prognostic factors in NEBC seem to not differ from those classically considered in other breast cancer subtypes [5]. Overall survival in these tumors is predicted by tumor size, lymph node status, and proliferation rate as judged by Ki-67 according to Tian et al. [22]. Otherwise, the limited number of NEBC cases in the reported series does not allow establishing significant correlations with specific prognostic factors.

\section{Conclusion}

Due to the rarity of the tumors, and their lack of defining clinical and radiological characteristics, the diagnosis of neuroendocrine breast carcinoma remains challenging. Currently, since the optimal treatment protocol is largely undefined, management of this entity should be similar to ductual carcinomas of the breast. Outcome of neuroendocrine breast carcinoma is also unclear. Further studies with careful collection of multicenter data may offer a better understanding of this unusual form of breast cancer.

\section{Conflict of Interest}

The authors declare no conflicts of interest.

The authors declare that they obtained informed consent from the patient to report the case.

\section{References}

[1] Adams, R.W., Dyson, P. and Barthelmes, L. (2014) Neuroendocrine Breast Tumours: Breast Cancer or Neuroendocrine Cancer Presenting in the Breast? Breast, 2, 120-127. https://doi.org/10.1016/j.breast.2013.11.005

[2] Ogawa, H., Nishio, A., Satake, H., Naganawa, S., Imai, T., et al. (2008) Neuroendocrine Tumor in the Breast. Radiation Medicine, 1, 28-32. https://doi.org/10.1007/s11604-007-0182-y

[3] Adegbola, T., Connolly, C.E. and Mortimer, G. (2005) Small Cell Neuroendocrine Carcinoma of the Breast: A Report of Three Cases and Review of the Literature. Journal of Clinical Pathology, 58, 775-778. https://doi.org/10.1136/jcp.2004.020792

[4] Tavassoli, F.A. and Devilee, P. (2003) Tumours of the Breast. World Health Organization Classification of Tumours, Pathology and Genetics of Tumours of the Breast and Female Genital Organs. IARC Press, Lyon, 32.

[5] López-Bonet, E., Alonso-Ruano, M., Barraza, G., Vazquez-Martin, A., Bernadó, L. and Menendez, J.A. (2008) Solid Neuroendocrine Breast Carcinomas: Incidence, Clinico-Pathological Features and Immunohistochemical Profiling. Oncology Reports, 20, 1369-1374.

[6] Rovera, F., Lavazza, M., La Rosa, S., Fachinetti, A., Chiappa, C., Marelli, M., et al. (2013) Neuroendocrine Breast Cancer: Retrospective Analysis of 96 Patients and Review of Literature. International Journal of Surgery, 11, S79-S83. https://doi.org/10.1016/S1743-9191(13)60023-0

[7] Vogler, E. (1947) Ueber das basilare Helle-Zellen-Organ der menschlichen Brustdruese. Klin Med Osterr $Z$ Wiss Prakt Med, 2, 159-168. 
[8] Cubilla, A.L. and Woodruff, J.M. (1977) Primary Carcinoid Tumor of the Breast. A Case Report of Eight Patients. The American Journal of Surgical Pathology, 1, 283-292. https://doi.org/10.1097/00000478-197712000-00001

[9] Günhan-Bilgen, I., Zegioglu, O., Ustun, E.E., Memis, A. and Erhan, Y. (2003) Neuroendocrine Differentiated Breast Carcinoma: Imaging Features Correlated with Clinical and Histophatological !ndings. European Radiology, 13, 788-793.

[10] Meciarová, I., Sojáková, M., Mego, M., Mardiak, J. and Pohlodek, K. (2016) High-Grade Neuroendocrine Carcinoma of the Breast with Focal Squamous Differentiation. International Journal of Surgical Pathology.

[11] Valentim, M.H., Monteiro, V. and Marques, J.C. (2014) Primary Neuroendocrine Breast Carcinoma: A Case Report and Literature Review. Radiologia Brasileira, 47, 125-127. https://doi.org/10.1590/S0100-39842014000200017

[12] Graça, S., Esteves, J., Costa, S. and Maciel, J. (2012) Neuroendocrine Breast Cancer. BMJ Case Reports.

[13] Brogi, E. (2014) Mammary Carcinomas with Endocrine Features. In: Hoda, S.A., Brogi, E., Koerner, F.C., Rosen, P.P., Eds., Rosen's Breast Pathology, 4th Edition, Lippincott Williams \& Wilkins, Philadelphia, 667-678.

[14] Lee, J.H., Park, A.Y., Seo, B.K., Kim, Y.S., Lee, K.Y. and Cha, S.H. (2015) Primary Neuroendocrine Carcinoma of the Breast with Clinical Features of Inflammatory Breast Carcinoma: A Case Report and Literature Review. Journal of Breast Cancer, 18, 404-408. https://doi.org/10.4048/jbc.2015.18.4.404

[15] Fujimoto, Y., Yagyu, R., Murase, K., Kawajiri, H., Ohtani, H., Arimoto, Y., et al. (2007) A Case of Solid Neuroendocrine Carcinoma of the Breast in a 40-Year-Old Woman. Breast Cancer, 14, 250-253.

[16] Mendez, P., Garcia, E., Rabadan, L., Pardo, R., Padilla, D. and Villarejo, P. (2012) Primary Neuroendocrine Breast Carcinoma. Clinical Breast Cancer, 12, 300-303. https://doi.org/10.1016/j.clbc.2012.03.001

[17] Sapino, A., Righi, L., Cassoni, P., Papotti, M., Pietribiasi, F. and Bussolati, G. (2000) Expression of the Neuroendocrine Phenotype in Carcinomas of the Breast. Seminars in Diagnostic Pathology, 17, 127-137.

[18] Rosa, M., Sheikh, S. and Nasir, A. (2016) Breast Carcinomas with Neuroendocrine Features (Neuroendocrine Carcinomas of the Breast). In: Nasir, A. and Coppola, D., Eds., Neuroendocrine Tumors. Review of Pathology, Molecular and Therapeutic Advances, 179-201. https://doi.org/10.1007/978-1-4939-3426-3_10

[19] Buttar, A., Mittal, K., Khan, A. and Bathini, V. (2011) Effective Role of Hormonal Therapy in Metastatic Primary Neuroendocrine Breast Carcinoma. Clinical Breast Cancer, 11, 342-345. https://doi.org/10.1016/j.clbc.2011.02.006

[20] Ochoa, R., Sudhindra, A., Garcia-Buitrago, M., Romilly, A.P., Cortes, J., Gomez, H., et al. (2012) Small Cell Cancer of the Breast: What Is the Optimal Treatment? A Report and Review of Outcomes. Clinical Breast Cancer, 12, 287-292. https://doi.org/10.1016/j.clbc.2012.03.007

[21] Wei, B., Ding, T., Xing, Y., Wei, W., Tian, Z., Tang, F., et al. (2010) Invasive Neuroendocrine Carcinoma of the Breast: A Distinctive Subtype of Aggressive Mammary Carcinoma. Cancer, 116, 4463-4473. https://doi.org/10.1002/cncr.25352

[22] Tian, Z., Wei, B., Tang, F., Wei, W., Gilcrease, M.Z., Huo, L., et al. (2011) Prognostic Significance of Tumor Grading and Staging in Mammary Carcinomas with Neuroendocrine Differentiation. Human Pathology, 42, 1169-1177. https://doi.org/10.1016/j.humpath.2010.11.014 


\section{Abbreviations}

NEBC: Neuroendocrine breast carcinomas;

MRI: Magnetic resonance imaging;

NSE: Neuron-specific enolase.

Submit or recommend next manuscript to OALib Journal and we will provide best service for you:

- Publication frequency: Monthly

- 9 subject areas of science, technology and medicine

- Fair and rigorous peer-review system

- Fast publication process

- Article promotion in various social networking sites (LinkedIn, Facebook, Twitter, etc.)

- Maximum dissemination of your research work

Submit Your Paper Online: Click Here to Submit

Or Contact service@oalib.com 